\begin{tabular}{|c|l|}
\hline Title & Long-term in situ observation of barnacle growth on soft substrates with different elasticity and wettability \\
\hline Author(s) & A hmed, Nafees; Murosaki, Takay uki; Kakugo, A kira; Kurokawa, Takayuki; Gong, Jian Ping; Nogata, Y asuyuki \\
\hline Citation & $\begin{array}{l}\text { Soft Matter, 7(16), 7281-7290 } \\
\text { https:/doi.org/10.1039/61sm05483j }\end{array}$ \\
\hline Issue Date & 2011-08-21 \\
\hline Doc URL & http://hdl.handle.net/2115/49233 \\
\hline Rights & Soft Matter, 2011, 7, 7281-7290- Reproduced by permission of The Royal Society of Chemistry (RSC) \\
\hline Type & article (author version) \\
\hline File Information & SM7-16_7281-7290.pdf \\
\hline
\end{tabular}

Instructions for use 


\section{Long-term in situ observation of barnacle growth on soft substrates with different elasticity and wettability}

Nafees Ahmed ${ }^{\mathrm{a}}$, Takayuki Murosaki ${ }^{\mathrm{b}}$, Akira Kakugo ${ }^{\mathrm{b}, \mathrm{c}}$, Takayuki Kurokawa ${ }^{\mathrm{b}, \mathrm{d}}$, Jian Ping Gong $^{\mathrm{b} *}$, Yasuyuki Nogata ${ }^{\mathrm{e}}$

${ }^{a}$ Laboratory of Soft \& Wet Matter, Division of Biological Sciences, Graduate School of Science, Hokkaido University, Sapporo, 060-0810 (Japan);

${ }^{b}$ Laboratory of Soft \& Wet Matter, Faculty of Advanced Life Science, Graduate School of Science, Hokkaido University, Sapporo 060-0810 (Japan);

${ }^{c}$ PRESTO, Japan Science \& Technology Agency (JST);

${ }^{d}$ Creative Research Institution, Hokkaido University, Sapporo, 001-0021 (Japan);

${ }^{e}$ Environmental Science Research Laboratory, Central Research Institute of Electric Power Industry, Abiko 270-1194, (Japan).

[*] Corresponding author: Tel/Fax: +81-11-706-2774, E-mail: gong@mail.sci.hokudai.ac.jp Key words: Barnacle, hydrogel, elastic modulus, wettability, antifouling, growth kinetics, self-release. 


\begin{abstract}
In this paper, settlement, metamorphosis, and long term growth of barnacle on soft substrates with a wide elasticity range (modulus $0.01-0.47 \mathrm{MPa}$ ) as well as with the variation of wettability were investigated for the first time in vitro, in the laboratory environment. Tough double-network (DN) hydrogels and polydimethylsiloxane (PDMS) were used as the soft hydrophilic substrates and hydrophobic substrates, respectively, and polystyrene (PS), a hard and hydrophobic substrate, was used as a control. It was observed that 1) the initial settlement and metamorphosis of cyprid larvae dramatically increases with the substrate elastic modulus while does not show an explicit dependence on the substrate wettability; 2) the growth rate of barnacles on both DN gels and PDMSs does not show an explicit dependence on the elasticity of the soft substrates, while it shows a slightly higher value on the hydrophobic PDMSs than on the hydrophilic DN gels; 3) the growth rate on these soft substrates is explicitly lower than that on the rigid PS substrate at the late state of the growth; 4) the "selfrelease" phenomenon of barnacles was observed for PDMS substrate with modulus higher than $0.01 \mathrm{MPa}$. Based on these observations, the antifouling effects of the soft substrates on barnacles were discussed.
\end{abstract}




\section{Introduction}

The fouling problems caused by marine sessile organisms (barnacles, shells, algae, diatoms, etc.) on the marine submerged solid surfaces, such as ship hulls, fish nets, power plants, have created great economic problems. To inhibit fouling by macrofoulers, several antifouling compounds have been developed. Tributyltin (TBT) is the most popular, and it exhibits high antifouling activity. However, TBT is banned worldwide since 2008 due to its high endocrine disruption effect ${ }^{1}$. There have been many efforts to develop new alternative antifouling materials to protect submerged surfaces. However, there are no suitable replacements for TBT currently available for widespread use ${ }^{2}$.

Some researchers ${ }^{3}$ conducted the settlement experiment of barnacle, Balanus improvisus, on PS substrate with different wettability and on the glass surfaces treated with highly hydrophilic and highly hydrophobic methylsilane. In these experiments advancing contact angle was measured with mQ water. It was observed that hydrophilic PS reduced settlement by $38 \%$ as compared to hydrophobic PS during 8 -day period whereas the cyprid settlement was completely inhibited by highly wettable methylsilane-treated glass (hydrophilic).

Several types of soft materials, such as polydimethylsiloxane (PDMS) and hydrogels, have been found to show antifouling properties.

Since 1980s, the antifouling behaviours of PDMS against barnacles have drawn great attentions $^{4-6}$. Wendt et al. ${ }^{7}$ investigated the growth of barnacle, Balanus amphitrite, in vitro for a long term of 3 months by measuring the basal size of barnacles. No relationship was found between coating thickness $(0.1 \sim 2.0 \mathrm{~mm})$ and the growth rate or the size of barnacle basal plates. Petronis et al. ${ }^{8}$ worked with micro-structured PDMS surface to investigate the settlement of barnacles on rough PDMS (about 67\%) rather than on smooth PDMS. However, neither the elastic modulus of PDMS substrates used nor the effect of the elasticity on the fouling behaviour was reported in these studies. Zhang et al. ${ }^{9}$ investigated the effect of elastic 
modulus $(0.43-2.35 \mathrm{MPa})$ of PDMS elastomer on the adhesion of diatom (Navicula $\mathrm{sp})$ and ulva spore (Pertusa) and the results revealed that the density of adhered diatoms and ulva spores have no relation with elastic modulus (E).

Recently, hydrogels are also drawing great interest as green antifouling materials. The antifouling activities of hydrogels against barnacle in vitro laboratory tests as well as in vivo in the marine environment have been performed. Rasmussen et al. ${ }^{10}$ studied in vitro that the hydrogels inhibited the settlement of cyprid larvae and reported that the polymer network, with respect to both polymer density and chemical structures, influenced the degree of inhibition. Recently, we have investigated the settlement of cyprid larvae on 14 kinds of hydrogels of different chemical structures in vitro ${ }^{11}$. We have revealed that except $\kappa$ carrageenan gel that showed a relatively high settlement, all kinds of hydrogels investigated exhibited substantial inhibition to the settlement of cyprid larvae. In addition, we envisaged that this antifouling activity might be related to the chemical structure of the hydrogels, and several kinds of hydogels, such as agarose gel, showed high antifouling activity without the dependence on their elastic moduli and water content, while others showed the dependence. Furthermore, we also investigated the antifouling behaviour of hydrogels in the marine environment.

Due to the fragile nature of hydrogels, only two kinds of tough hydrogels, polyvinyl alcohol (PVA) hydrogel and PAMPS/PAAm double network (DN) hydrogel, survived the marine test for 330 days without any damage ${ }^{12}$. These two gels showed substantial antifouling activity against barnacles either in terms of settlement density or in the basal size (smaller) in comparison with the polyethylene that was used as a solid reference.

The antifouling activity of a material against barnacles would occur based on 3 mechanisms: 1) Low or inhibited settlement of cyprid larvae; 2) Slow or inhibited growth of barnacle; 3) Easy-release of the barnacle during the growth. In the laboratory environment, most of the 
studies have been performed either on the initial settlement of cyprid larvae or growth of acorn barnacle, where the antifouling result is due to the mechanism 1 and mechanism 2 , respectively. On the other hand, in the marine environment, the observation usually performed on the outgrown stage, where the result is due to all of the 3 mechanisms. A longterm, real time study on the whole process of the cyprid larvae settlement, metamorphosis, and barnacle growth to adult on the antifouling substrates will substantially favour the understanding of the barnacle fouling mechanism.

In this study, we design an experiment to observe the settlement, metamorphosis, and growth process of barnacles, in real time and for long term (70 days), on soft substrates with different elasticity and wettability. The soft materials that have certain but not complete antifouling activity should be used in order to ensure the observation of the whole growth process of barnacles. Double-network (DN) hydrogels and PDMS, the two substrates that showed certain degree of antifouling behaviours against barnacles in vitro and in vivo, were chosen as the soft hydrophilic and hydrophobic substrates, respectively. The elasticity of these two kinds of soft substrates is tuned over a wide range (modulus 0.01-0.47 $\mathrm{MPa}$ ). To make a comparison, polystylene (PS) was used as the hard substrate.

\section{Materials and methods}

\subsection{Reagents}

2-Acrylamide-2-methylpropanesulfonic acid (AMPS) was courtesy of Toagosei (Tokyo, Japan), acrylamide (AAm) was purchased from Junsei Chemical Co. Ltd, Tokyo Kasei Kogyo (Tokyo, Japan) as a crosslinking agent was purified by recrystallization from ethanol. 2-oxiglutaric acid (Wako pure Chemicals, Osaka, Japan), an initiator of free radical polymerization, was used as purchased. The precursor of PDMS (Sylgard $184^{\mathrm{TM}}$ ) W/C base resin and the cross linker of PDMS (catalyst of sylgard 184) (Dow Corning Toray Co. Ltd.) were used as purchased. 


\subsection{Preparation of the substrates}

\subsubsection{DN gels}

PAMPS/PAAm DN gels were synthesized using a two-step sequential network formation technique $^{13}$. As the first step, PAMPS gel (first network) was synthesized from a $1 \mathrm{M}$ monomer aqueous solution containing $3 \mathrm{~mol} \% \mathrm{MBAA}$ and $0.1 \mathrm{~mol} \%$ 2-oxoglutaric acid by radical polymerization as described above. The gel was immersed in a $2 \mathrm{M}$ AAm aqueous solution containing $0.01 \mathrm{~mol} \%$ 2-oxigluteric acid for at least 1 day until equilibrium was reached. After the swollen gel was taken out of the AAm solution, the second network (PAAm) was subsequently polymerized in the presence of the first network gel (PAMPS) under irradiation of UV light for $8 \mathrm{~h}$ between two plats of glass between which silicone spacer of $1 \mathrm{~mm}$ of thickness was placed. The PAMPS sample was denoted as PAMPS (1-30.1)/PAAm (2-0-0.01), where the numbers in the parenthesis are the concentration of monomer (M), crosslinker ( $\mathrm{mol} \%$ in relative to monomer), and initiator ( $\mathrm{mol} \%$ in relative to monomer), respectively. Similar method was applied in the case of synthesizing PAMPS (14-0.1)/ PAAm (2-0-0.01) gel and PAMPS (1-1-0.1)/ PAAm (5-0.03-0.01).

After gelation, DN gels were immersed in a large amount of autoclaved seawater for sufficient time to remove residual chemicals (about 1 week) and the autoclaved seawater was changed at least once each day. The resulting thickness of the gels was $\approx 2.0 \mathrm{~mm}$. PAMPS/PAAm gels were colourless and transparent.

\subsubsection{PDMS elastomer}

PDMS elastomer was prepared according to commercially available product instructions. After degassing, a mixed solution of the precursor and crosslinker in weight ratios of 1.5, 2.0, 2.5, 3.0, 3.5 and $4.0 \%$ was poured in the polystyrene (PS) petri dish (outer diameter of 83.7 $\mathrm{mm}$, height of $15 \mathrm{~mm}$ ) (Nunclon) adjusting the volume to keep the thickness up to about 2 $\mathrm{mm}$. Polymerization was then carried out at $60^{\circ} \mathrm{C}$ for $8 \mathrm{~h}$. 


\subsection{Modification of DN gels}

The parent PAMPS/PAAm DN gels of three different compositions (1-1-0.1/5-0.03-0.01; 1$3-0.1 / 2-0-0.01$, and 1-4-0.1/2-0-0.01) were cut into disk shape (15 mm diameter; $\approx 2.0 \pm 0.2$ mm thickness) and were modified by compression at different strains to get the DN gels of variable elastic moduli using a tensile-compressive tester (Tensilon RTC-1310A; Orientec, Co.). After the compression the gels were immersed in the autoclaved seawater for 1 day and were then made ready for determining the elastic modulus. Other sets of DN gels were cut into $81.5 \mathrm{~mm}$ of diameter and were compressed in similar manner followed by the immersion into autoclaved seawater for one day. The second sets of DN gels were used for the barnacle settlement and growth process investigation. This compression technique was chosen to soften the elastic modulus of the DN gel to various level by partially destroying the internal structure of the first rigid network PAMPS, as proved by our previous work ${ }^{14}$.

\begin{tabular}{|c|c|c|c|c|c|c|}
\hline Type & Wettability & $\begin{array}{l}\text { Sample } \\
\text { code }\end{array}$ & Composition & $\begin{array}{c}\text { Elastic } \\
\text { modulus } \\
(\mathrm{MPa})\end{array}$ & $\begin{array}{c}\text { Water } \\
\text { content } \\
(\%)\end{array}$ & $\begin{array}{c}\text { Contact angle } \\
\left({ }^{\circ}\right)\end{array}$ \\
\hline \multirow{12}{*}{ Soft } & \multirow{6}{*}{$\begin{array}{l}\text { Hydrophobic } \\
\text { (PDMS) }\end{array}$} & PDMS_0.01 & $1.5 \mathrm{wt} \%$ & 0.01 & 0 & $60 \pm 4.4$ \\
\hline & & PDMS_0.05 & $2.0 \mathrm{wt} \%$ & 0.05 & 0 & $68 \pm 7.4$ \\
\hline & & PDMS_0.09 & $2.5 \mathrm{wt} \%$ & 0.09 & 0 & $74 \pm 8.5$ \\
\hline & & PDMS_0.22 & $3.0 \mathrm{wt} \%$ & 0.22 & 0 & $78 \pm 8.1$ \\
\hline & & PDMS_0.37 & $3.5 \mathrm{wt} \%$ & 0.37 & 0 & $90 \pm 0.8$ \\
\hline & & PDMS 0.47 & $4.0 \mathrm{wt} \%$ & 0.47 & 0 & $89 \pm 0.7$ \\
\hline & \multirow{6}{*}{$\begin{array}{l}\text { Hydrophilic } \\
\text { (DN Gel) }\end{array}$} & DN_0.01 & $\begin{array}{c}1-1-0.1 / \\
5-0.03-0.01\end{array}$ & 0.01 & 89 & $22 \pm 1.6$ \\
\hline & & DN_0.05 & $\begin{array}{c}1-1-0.1 / \\
5-0.03-0.01\end{array}$ & 0.05 & 87 & $18 \pm 2.0$ \\
\hline & & DN_0.09 & $\begin{array}{l}1-3-0.1 / \\
2-0-0.01\end{array}$ & 0.09 & 91 & $20 \pm 1.0$ \\
\hline & & DN_0.21 & $\begin{array}{c}1-1-0.1 / \\
5-0.03-0.01\end{array}$ & 0.21 & 88 & $21 \pm 1.2$ \\
\hline & & DN_0.33 & $\begin{array}{l}1-3-0.1 / \\
2-0-0.01\end{array}$ & 0.33 & 90 & $17 \pm 2.7$ \\
\hline & & DN_0.47 & $\begin{array}{l}1-4-0.1 / \\
2-0-0.01\end{array}$ & 0.47 & 90 & $19 \pm 3.2$ \\
\hline Hard & $\begin{array}{l}\text { Hydrophoibic } \\
\text { (Polystyrene }\end{array}$ & PS & - & 3000 & 0 & $78 \pm 1.0$ \\
\hline
\end{tabular}


Table 1: Properties of different substrates used in this study. The standard deviation of elastic modulus was within \pm 0.01 .

\subsection{Determination of the elastic modulus}

The elastic modulus of PAMPS/PAAm DN gels and PDMS were determined using a compressive test with a tensile-compressive tester (Tensilon RTC-1310A; Orientec, Co.). The samples were compressed with two parallel metal plates connected to a load cell at a strain rate $20 \% \mathrm{~min}^{-1}$. The elastic modulus was determined by the average slope of the stress-strain curve over the strain ratio range of $0-0.01$. All the samples were coded with their elasticity, as shown in Table 1.

\subsection{Measurement of water content of DN gels}

The water content of DN gels shown in Table 1 was measured by the weight change upon drying using the electronic moisture balance (Shimazu Co., Kyoto, Japan) that evaporates the water in the gel at $150^{\circ} \mathrm{C}$. The detailed procedures were described in our previous research work $^{15}$.

\subsection{Measurement of water contact angle}

The water contact angle on different substrates was measured by applying optical tensiometry (goniometry). The substrate was mounted on the stage of the tensiometer (Drop Master 300, Kyowa Interface Science Co., LTD, Saitama, Japan) and then the sessile drop of water droplet of $1.0 \mu \mathrm{L}$ in volume was put on the substrate. The contact angle was measured after 15-20 seconds of casting the drop on the substrate. Only the static contact angle was measured. The results are given in the Table 1.

In this experiment the substrates that we used were prepared on the glass substrates. The roughness of the glasses was $2-5 \mathrm{~nm}$, and the hydrogels synthesized on the glass substrates were several decades of nanometers, due to the swelling of the gel in water that increased the roughness ${ }^{16,17}$. In relative to the antennules of cyprid larvae of barnacle that is about several 
decades of micrometers, the hydrogel surfaces can be considered as flat and smooth, and there is no any roughness effect on the settlement and the growth of barnacle ${ }^{18}$. Because of this reason we did not concern about the roughness of the substrate on the settlement and the growth of barnacle in this work.

\subsection{Preparation of cyprid larvae}

The Balanus amphitrite cyprid larvae were cultured according to standard procedures ${ }^{19}$. Briefly, adult B. amphitrite brood stocks were maintained in plastic 10-L aquaria with aeration at a controlled temperature of $25^{\circ} \mathrm{C}$, and were fed with a daily diet of naupliar larvae of the brine shrimp Artemia salina. Nauplii come out after the stimulation of the adults inside the incubator (LPH-100S; NK System, Japan) about 12 hours at $25^{\circ} \mathrm{C}, 80 \%$ of humidity, followed by changing the seawater within 30 min to few hours. A concentrated light source was provided without aeration to collect photopositive nauplii. Nauplii were collected by pipette and transferred to a beaker at a density of 4 larvae $\mathrm{mL}^{-1}$ and fed daily with the diatom Chaetoceros gracilis. The concentration of diatoms in the beaker was kept at $15 \times 10^{4}$ cells $\mathrm{mL}^{-1}$ at a temperature of $25^{\circ} \mathrm{C}$ with a photoperiod of $8 \mathrm{~h}$ light and $16 \mathrm{~h}$ dark. A mixture of streptomycin and penicillin was added to the beaker at the beginning of the culture to prevent bacterial growth. After 5 days, the culture was filtered through plankton sieves to separate the cyprids from the nauplii. Cyprids were kept at $6^{\circ} \mathrm{C}$ in the dark in autoclaved seawater for two days before the settlement assays were carried out. Autoclaved seawater $\left(120^{\circ} \mathrm{C}, 20 \mathrm{~min}\right)$ was used in all experiments.

\subsection{Settlement assay}

\subsubsection{Polystyrene petri dish system}

PS petri dish (NunclonTM Delta) with the dimension of $82.5 \mathrm{~mm}$ in inside diameter was used as the settlement and growing system of barnacles. The bottom of each dish was coated with 
the parent and modified DN gels (previously cut and compressed) after the gels had been immersed in autoclaved seawater for one day. Other sets of PS petri dish were coated with PDMS elastomer since beginning. As previously clarified that agarose gel has complete antifouling property ${ }^{10,11}$ against barnacle, it was used as the coating material of the inside wall of PS petri dish to inhibit the settlement. The coating of agarose gel was prepared by dissolving the polymer powder in $\mathrm{mQ}$ water in a weight ratio $4 \%$ being stirred for $15 \mathrm{~min}$ at $90^{\circ} \mathrm{C}$. The hot solution of agarose gel was first poured in the gap between the inside wall of the dish and the acrylic mould of $80 \mathrm{~mm}$ in diameter. Then the dishes were kept at $4^{\circ} \mathrm{C}$ in the low temperature room for 10-15 min to cool down. After being cooled down the moulds were removed from the petri dish and the dishes were then immersed in large amount of autoclaved seawater for two days in order to leach out the residuals in agarose gel. The autoclaved seawater was changed twice a day.

\subsubsection{Settlement experiment}

After two days of the immersion in the autoclaved seawater, the PS petri dishes coated with PAMPS/PAAm DN gels and PDMS at the bottom and with agarose gel on the wall, were taken out and used as the settlement bed for the cyprid larvae. Bare PS bottom of the petri dishes was used as control. As the cyprid larvae are photopositive, so the outside wall and the lid of the PS petri dishes were wrapped by black coloured vinyl tape to prevent the penetration of light into the petri dishes. About $7 \mathrm{~mL}$ of autoclaved seawater containing $100 \pm$ 10 of 2-day aged cyprid larvae was poured into each petri dish. The larvae loaded petri dishes were cultured in an incubator (LPH-100S; NK System, Japan) and held at a temperature $25^{\circ} \mathrm{C}$ with a photoperiod of $8 \mathrm{~h}$ light under a cool white fluorescent lamp and $16 \mathrm{~h}$ dark for 7 days. Cyprid larvae of $B$. amphitrite, having the tendency to explore suitable surface for the settlement, were used for all settlement test. Cyprids that had metamorphosed into juvenile 
barnacles were termed as "settled" in this study, as illustrated schematically in the Fig. 1. A number of cyprids was found to settle on the bottom of the petri dishes coated with DN gels and PDMS, as well as on bare PS bottom. No cyprid was found to settle on the wall surface covered by the agarose gel. The settled cyprids or juvenile barnacles were enumerated by using a stereomicroscope (SZX-12; Olympus, Japan) at 1, 3, 5 and 7 day after loading.

\subsection{Observation of the barnacle growth}

After 7 days settlement when cyprid larvae on all the substrates had metamorphosed into juvenile barnacle, the agarose gel coating was removed from the inside wall of the petri dishes, and the petri dishes were transferred to a $6.5 \mathrm{~L}$ plastic vessel filled with autoclaved seawater. The barnacles were fed with diatom, Chaetoceros gracilis, up to one month. The

concentration of diatoms in the vessel was maintained at $\approx 25 \times 10^{4}$ cells $\mathrm{mL}^{-1}$ at a temperature of $25^{\circ} \mathrm{C}$ with a photoperiod of $8 \mathrm{~h}$ light and $16 \mathrm{~h}$ dark. The day of the growth of acorn barnacle was considered to start from day 7 of the metamorphosed settled barnacles and it was set as day 0 of the growing process of barnacle. Under the conditions mentioned above, the barnacles growing inside the petri dishes were observed. The basal shape, size, and morphology were recorded by using EPSON GT-X700 scanner after two weeks each. The size of the barnacles was analyzed by using image analyzing software Image-Pro Plus 6.1. After one month when the barnacle became little bigger in size about $2.5 \mathrm{~mm}$ in basal diameter, they were fed with the nauplii of brine shrimp, Artemia salina. The concentration of the brine shrimp was maintained at about $560 \pm 70$ nauplii $\mathrm{mL}^{-1}$. The growth observation was continued for 70 days. 


\section{Results and discussion}

\subsection{Barnacle settlement test}

Cyrprid larvae were found to settle on all the substrates starting from the first day since their exposure, and increased with the exposure time (Fig. 2a). On day 7, about $43 \%$ the loaded cyprids settled on the PS surface and metamorphosed into juvenile barnacles; while the settlement ratio on the soft substrates was much lower, $2-30 \%$ and $2-29 \%$ on DN gels and PDMSs, respectively (Fig. 2a). For both PDMS and DN gels the settlement and the metamorphosis of cyprid larvae was lower on the substrate with low elastic modulus than that on higher elastic modulus. However, within the experimental error range, no explicit difference of settlement was observed for DN gel and PDMS substrates as shown in Fig. $2 \mathrm{~b}$. The hydrophobic or hydrophilic properties of the substrates have no influence on the settlement of barnacles. It was confirmed that no barnacle was observed on the wall surface covered with agarose gel. The cyprids settlement behaviour on these substrates is in agreement with the previous findings ${ }^{11}$.

\subsection{Growth of barnacles on different substrates}

\subsubsection{Size distribution}

Figure 3 shows the distribution of barnacle basal diameter on the 3 kinds of substrates at various time of culture. For simplicity, results on soft substrates with the highest modulus $(0.47 \mathrm{MPa})$ and the lowest modulus $(0.01 \mathrm{MPa})$ were shown. Other results on the substrates with a modulus between them are similar. On day 0 (just before starting of feeding, in juvenile state), the basal diameter of barnacles was about $500 \mu \mathrm{m}$. On day 70 , the average basal size were $5.29 \mathrm{~mm}, 2.98-4.06 \mathrm{~mm}$ and $3.14-3.38 \mathrm{~mm}$ on PS, PDMSs and DN gels surfaces, respectively. In initial stage (juvenile state), the size distribution of barnacles on all of the substrates is comparatively narrow. However, it becomes broader with the elapse of time on PS substrate. On the other hand, the size distribution on soft substrates (PDMSs and 
DN gels) was narrower compared to that on PS even in mature state (Fig. 3). The results indicate that the wettability and elasticity of the soft substrates do not affect the size distribution of barnacles, while the barnacles do show a different behaviour on these soft substrates in comparison with the hard PS substrate.

\subsubsection{Growth rate of barnacles}

In this experiment, barnacle growth was observed over two months, in two periods with different feeding conditions. In the first one month of the experiment, barnacles were fed once in each three days with the diatom, "Chaetoceros gracilis". After the first one month, barnacles were fed once in each three days with brine shrimp, "Artemia salina", because by that time they became big enough to be able to prey zooplankton.

Figure 4 shows the time evolution of the basal size of barnacles on each substrate. Starting from the initial diameter about $500 \mu \mathrm{m}$ at day 0 on all types of substrates, the barnacles grew fast at the initial stage with diatom-feeding, until about 20 days. Then the growth rate remarkably slowed down from day 20 to day 30. In the case of PDMSs surfaces, the growth rate was slightly higher compared to PS and DN gels in the initial 14 days. On DN gels, the size of barnacles was smallest among all of the substrates in the initial period. On PS surface the barnacle growth rate was lying between those of the former substrates. The authors hypothesized that surface tension might affect the growth of juveniles. Surface tension of $\mathrm{PS}^{20}$ and $\mathrm{PDMS}^{21}$ are $36 \mathrm{mN} \mathrm{m}^{-1}$ and $20-30 \mathrm{mN} \mathrm{m}^{-1}$, respectively. On the other hand, the surface tension of DN gel is close to that of water $\left(72 \mathrm{mN} \mathrm{m}^{-1}\right)$. The growth rate of juveniles might decrease with the surface tension of the corresponding substrates. However, the elastic modulus of the substrates shows no explicit effect on the growth rate in this initial growth stage.

At the second period after feeding with brine shrimp, the growth of barnacles on PS surface showed quick increase again, whereas the growth on soft substrates was much slow. This 
result is in agreement with our previous in vivo observation that revealed a smaller basal size of barnacles on hydrogels than on solid substrates ${ }^{12}$.

Growth rate was calculated from slopes of the growth curve at two different phases, the first and the second month growth phase. During first month growth profile, the absolute growth rates of barnacles were measured to be $12.39 \times 10^{-2} \mathrm{~mm} \mathrm{~d}^{-1}, 11.52 \times 10^{-2} \mathrm{~mm} \mathrm{~d}^{-1}$, and $10.93 \times$ $10^{-2} \mathrm{~mm} \mathrm{~d}^{-1}$ on PDMS, PS, and DN gel, respectively, up to 28th day from the slope of the growth curve (Fig. 4). In the second month growth profile, the growth rate of barnacles on PDMS and DN gel were measured to be $1.53 \times 10^{-2} \mathrm{~mm} \mathrm{~d}^{-1}$ and $1.24 \times 10^{-2} \mathrm{~mm} \mathrm{~d}^{-1}$, respectively. On the other hand, the growth rate of barnacles on PS surface was calculated to be $5.47 \times 10^{-2} \mathrm{~mm} \mathrm{~d}^{-1}$, several times higher than that on soft substrates.

\subsubsection{Influence of elasticity of the substrates on the basal size of barnacles}

As shown in Figure 5, for the substrates with elasticity varied from $0.01 \mathrm{MPa}$ to $0.47 \mathrm{MPa}$, the elastic modulus of PDMS and DN gels had no significant effect on the average basal diameter of barnacles at the initial (14 days), middle (42 days), and long(70 days) growing periods (Figure 5a, 5b, and 5c). On the other hand, barnacles showed a slightly larger basal diameter on the hydrophobic PDMS surface than on the hydrophilic DN gel and on the PS substrate at the initial growth stage. However, with the increase in the growth time, the barnacles on the PS increased faster, and at day 70, they showed much larger diameter on PS than on PDMSs and DN gels.

\subsubsection{Self-release phenomenon of barnacle during growth}

During long-term observation (over two months), the decreasing of settlement number was found (Fig. 3), and it is due to the death of settled barnacle and detachment of barnacle from the substrate. The detachment caused by following two cases; accidentally peeled off by 
experimenter during handling (accidental release), and spontaneous detachment by the barnacles from the surface (self-release).

In the case of PS, the decrease of the number of juvenile barnacles during the experimental period was only due to their death, whereas in the case of DN gels few barnacles were accidentally released (Fig. 3). The death of the juvenile barnacles on PS surface was confirmed by observing their stagnant appearance even after spraying of water on them. On PDMS surface barnacle detachment occurred only by self-release as the day advanced.

Fig. $6(a, b)$ shows the time evolution of the self-release ratio and the basal diameter of the released barnacles from PDMS substrate with different elasticity. From these figures two factors were clarified, one is time factor and another is size factor. Self-release of barnacles from PDMS surfaces was observed to start from day 35 and the average size at which the release began was over $2 \mathrm{~mm}$. This finding suggests that self-release is easy to occur without dependence of elasticity of PDMS when barnacle size is over $2 \mathrm{~mm}$. When the barnacles reach the basal size of $2 \mathrm{~mm}$ in diameter after one month their metabolic activity might increase and they spontaneously respond to the environment by exploring the cirri for taking food or preying. As barnacles grow their muscles become mature. During exploring the cirri their muscles contract and extend. At the time of back and forth movement of cirri it creates some pressure on the base plate of barnacle through muscle contraction. When the cirri are moved upward for eating food or preying and are explored in one direction, the muscle of the same side of the direction of the movement of cirri contracts and depresses on the base plate. At the same time there is some tension generated on the base plate through the extension of the muscle on the opposite side of the direction of the movement of cirri. As barnacle has low adhesion strength against PDMS, the authors speculated that barnacles are prone to release from the non-stick PDMS substrates due to the extension-contraction of their body muscle. 
And thus self-release phenomenon occurs. Self-release did not occur on PDMS with elastic modulus of $0.01 \mathrm{MPa}$ because of its stickiness.

Fig. 7 shows self-release ratio and basal diameter of detached barnacles as a function of elastic modulus of PDMS substrates at 70 days. This figure shows that PDMS has maximum self-release property when its elastic modulus is about $0.09 \mathrm{MPa}$. Other researchers reported that barnacles exhibit low adhesion property on $\mathrm{PDMS}^{22}$. Though the "easy-release" phenomenon of fouling organism from silicone surface has been investigated regarding the critical surface tension $^{21}$, the effect of the critical elastic modulus of PDMS has not been observed so far either in laboratory assay or in the field test.

In this experimental environment, there is no interfering effect, i.e., tidal wave or friction. So, it can be said that the low adhesion of barnacle on PDMS is responsible for this self-release. On the other hand, no self-release phenomenon was observed on PS and DN gels. On PS, which is solid material, barnacles may be able to form strong adhesion. Thus, these findings indicate that the order of barnacle adhesion strength is PS, DN Gel, and PDMS. The weak adhesion of the barnacles on the PDMS surface was justified by the amount of cement secreted from the barnacles to the surface, as can be recognized by eyes. As shown in Figure 8, the basal plate morphology of barnacles is quite different on the PS, PDMS, and DN gel. Concentric and radial patterns were clearly observed on the PS substrate, indicating that the bonding of the barnacle basal with the PS substrate was via a very thin layer of cement proteins. On the DN gel, a very fuzzy pattern can be recognized, which is related to a relatively thicker layer of cement proteins. The basal morphology became opaque on the PDMS substrate, which is related to a large amount of cement proteins secreted on the PDMS surface to keep the barnacle stick to the surface as much as possible. The result that the barnacles have stronger adhesion to the hydrophilic DN gel than to the hydrophobic PDMS is in agreement with the previous observations in literature ${ }^{21,22}$. It has been reported that the 
adhesion strength of barnacles on some hydrophilic substrates is high ${ }^{23}$. Baier ${ }^{21}$ inferred that the fully hydrated polyethylene oxide (PEO) materials fail to resist biofouling in practical situation for longer period of time. They assume that this is caused by the displacement of bound water on the surface of PEO by multiple side chains of macromolecular proteins which are exposed to the highly oxygenated surfaces with intrinsically high critical surface tension. Furthermore, they also commented that some synthetic hydrogels are among the most fouling persistent substances ever tested after long-term contact with biological systems. Similar explanation can be considered in the case of the adhesion of barnacle on hydrophilic DN gel. Barnacles, secreting adult cement protein, firmly attach with DN gel once they settle. During their growth due to the continuous displacement of bound water on DN gel surface by the cement protein, barnacles tend to adhere more strongly on the surface. As a result, no selfrelease occurred on DN gel.

\subsubsection{Discussions}

The different growth kinetics of barnacles on hard (PS) and soft (PDMSs and DN gels) substrates at the second growth profile described in section 3.2 .2 can be illustrated by considering two factors, adhesion strength of barnacles on the substrates and elasticity of the substrates. As the adhesion strength of barnacles on PS is much higher compared to that on PDMSs and DN gels, there is no possibility of their easy-release from PS surface. As a result, they are very prone to settle and keep themselves stick to PS surface. On the other hand, due to very high elastic modulus $(3000 \mathrm{MPa})$, PS exposed as stiffer substrate and does not undergo deformation by the contraction of the depressor muscle of barnacle during growing. These two factors enhanced the growth of barnacle on PS.

The growth of barnacle on PDMS can be explained in different aspect. Barnacles grown on PDMS exert some force through their muscle contraction on the surface. As PDMS was coated on PS, it firmly attaches with PS. Because of this, PDMS can no longer undergo 
deformation in the form of bending due to the force generated by the barnacle depressor muscles. Due to very weak adhesion on PDMS, barnacles tended to detach from the surface during growing. In order to compensate the gap created at the interface between the surface and the basis, barnacle secret large amount of cement protein to keep them stick to the surface. Because of this detachment-attachment process barnacle growth becomes inhibited. Moreover, the self-release tendency also plays an important role in the slower growth of barnacle on PDMS.

On the other hand, as a hydrophilic and soft $(E=0.01-0.47 \mathrm{MPa})$ substrate, DN gel undergoes deformation in the form of bending when barnacles exert force on the gel through depressor muscle during the growth. Because of strong adhesion on DN gel, barnacles become slightly trapped and due to the bending of DN gel during further growing, their growth becomes slower and slower little by little. So, the growth rate of barnacles on DN gels was found to be much lower compared to other two substrates, PS and PDMS.

Our previous in vivo observation in the marine environment revealed a smaller basal size of barnacles on PVA and DN hydrogels than on solid substrates, and this phenomenon was explained in terms of "easy-release" 12 . However, the present study indicates that on hydrogels, the "easy-release" would hardly occur, and the smaller basal size observed in the previous study on hydrogels is due to a slow growth mechanism.

\subsubsection{A summary on the antifouling activity of different substrates}

It can be said that the concept of antifouling property of the substrate comprises not only the lower settlement of barnacle but also the slower growth rate and the self-release tendency of barnacle from the substrate. In this connection PS was observed to be highly fouled by barnacles in all of these three mechanisms. Though barnacle settlement was found to be little higher on PDMSs than on DN gels at pre-metamorphosed state, the slower growth and the self-release property of barnacle from PDMSs makes them highly antifoulant. Despite the 
non-self-release tendency observed on DN gels, comparatively higher growth inhibitory activity has made DN gel one of the best antifouling agents against barnacle. Moreover, for both PDMS and DN gel, the settlement of barnacles on very soft surfaces $(E=0.01,0.05$ and $0.09 \mathrm{MPa}$ ) has turn them to be effective antifouling agents against barnacle. The antifouling properties of these substrates are summarized in Table 2.

\begin{tabular}{|c|c|c|c|c|c|}
\hline \multirow{2}{*}{\multicolumn{2}{|c|}{ Substrates }} & \multirow{2}{*}{$\begin{array}{l}\text { Elastic Modulus } \\
\qquad(\mathrm{MPa})\end{array}$} & \multicolumn{3}{|c|}{ Antifouling Properties } \\
\hline & & & $\begin{array}{c}\text { Settlement } \\
\text { inhibition }\end{array}$ & $\begin{array}{c}\text { Growth } \\
\text { inhibition }\end{array}$ & Self-release \\
\hline \multirow{12}{*}{ Soft } & \multirow{6}{*}{ DN Gel } & 0.01 & +++ & +++ & - \\
\hline & & 0.05 & +++ & +++ & - \\
\hline & & 0.09 & ++ & +++ & - \\
\hline & & 0.21 & + & +++ & - \\
\hline & & 0.33 & + & +++ & - \\
\hline & & 0.47 & + & +++ & - \\
\hline & \multirow{6}{*}{ PDMS } & 0.01 & +++ & +++ & - \\
\hline & & 0.05 & +++ & ++ & ++ \\
\hline & & 0.09 & +++ & +++ & +++ \\
\hline & & 0.22 & + & +++ & + \\
\hline & & 0.37 & + & +++ & +++ \\
\hline & & 0.47 & + & ++ & + \\
\hline Hard & PS & 3000 & - & - & - \\
\hline
\end{tabular}

[N.B.: $+++=$ extremely high, $++=$ high; $+=$ low; $-=$ not observed. $]$

Table 2. Antifouling properties of different substrates.

\section{Conclusions}

Though PDMS (hydrophobic) and PAMPS/PAAm DN gel (hydrophilic) exhibited the increment of the settlement of pre-metamorphosed barnacle (cyprid larvae) with their corresponding increase in elastic moduli, however, the growth of barnacles on both of these substrates was found to be independent on the elastic modulus of the substrate. Furthermore, "self-release" tendency of barnacles from the hydrophobic PDMS surface at postmetamorphosed state proved the high antifouling activity of PDMS against barnacle. On the other hand, PDMS as well as PAMPS/PAAm DN gel exhibited growth inhibitory activity which was evidenced by comparing the growth rate of barnacles on hard substrate (PS) 
(about 4 times higher) with that on PDMS and DN gels (both of them were nearly the same) after more than two months observation of the growth kinetics.

\section{Acknowledgment}

This work is supported by a Grant-in-Aid for the Specially Promoted Research (No. 18002002)

from the Ministry of Education, Science, Sports, and Culture of Japan. 


\section{References}

1. IMO, International Maritime Organization [Internet], Resolutions summaries, 1999, A.895(21); [cited 2009 Jun 16$]. \quad$ Available from:http://www5.imo.org/SharePoint/blastDataHelper.asp/data_id\%3D24284/895\%28 21\%29.PDF.

2. L. D. Chambers, K. R. Stokes, F. C. Walsh, R. J. K. Wood, "Modern approaches to marine antifouling coatings", Surface \& Coatings Technology, 2006, 201:, 3642-3652.

3. M. Dahlstrom, H. Jonsson, Per R. Jonsson and H. Elwing, "Surface wettability as a determinant in the settlement of the barnacle Balanus Improvisus (DARWIN)", Journal of Experimental Marine Biology And Ecology, 2004, 305, 223-232.

4. A. Milne and M. E. Callow, "Non-biocidal antifouling processes", Polymer in a Marine Environment (ed. R Smith), 1985, 229-233; The Institute of Marine Engineers, London.

5. R. F. Brady Jr, J. R. Griffith, K. S. Love and D. E. Field, "Nontoxic alternatives to antifouling paints", J Coat Technol, 1987, 59, 113-119.

6. H. L. Vincent, and G. G. Bausch, "Silicone fouling release coatings", Naval Research Reviews, 1997, 4, 39-45.

7. D. E. Wendt, G. L. Kowalke, J. Kim and I. L. Singer, "Factors that influence elastomeric coating performance: the effect of coating thickness on basal plate morphology, growth and critical removal stress of the barnacle Balanus amphitrite", Biofouling, 2006. 22(1/2), 1-9.

8. Š. Petronis, K. Berntsson, J. Gold and, P. Gatenholm, "Design and microstructuring of PDMS surfaces for improved marine biofouling resistance", Journal of Biomaterials Science, Polymer Edition 2000, 11, 1051-1072 (22).

9. J. Zhang, C. Lin, L. Wang, J. Zheng, W. Peng and D. Duan, "The Influence of Elastic Modulus on the Adhesion of Fouling Organism to Poly(dimethylsiloxane) (PDMS)", Advanced Materials Research, 2011, 152-153, 1466-1470.

10. K. Rasmussen, P. R. Willemsen and K. Østgaard, "Barnacle settlement on hydrogels", Biofouling, 2002, 18(3), 177-191.

11. T. Murosaki, T. Noguchi, A. Kakugo, A. Putra, T. Kurokawa, H. Furokawa, Y. Osada, J. P. Gong, Y. Nogata and K. Matsumura, E. Yoshimura, N. Fusetani, "Antifouling activity of synthetic polymer gels against cyprids of the barnacle (Balanus amphitrite) in vitro", Biofouling, 2009, 25, 313-320.

12. T. Murosaki, T. Noguchi, K. Hashimot, A. Kakugo, A. Putra, T. Kurokawa, J. Saito, Y. M. Chen, H. Furokawa and J. P. Gong, "Antifouling properties of tough gels against barnacles in a long-term marineenvironment experiment", Biofouling, 2009, 25, 657666. 
13. J. P. Gong, Y. Katsuyama, T. Kurokawa and Y. Osada, "Double-network hydrogels with extremely high mechanical strength", Adv Mater, 2003, 15, 1155-1158.

14. Y. Tanaka, R. Kuwabara , H. N. Yang -, T. Kurokawa, J. P. Gong and Y. Osada, "Determination of Fracture Energy of High Strength Double Network Hydrogels", J. Phys. Chem.B, 2005, 109(23), 11559-11562.

15. H. Itagaki, T. Kurokawa, H. Furukawa, T. Nakajima,Y. Katsumoto and J. P. Gong, "WaterInduced Brittle-Ductile Transition of Double Network Hydrogels", Macromolecules, 2010, 43 (22), 9495-9500.

16. T. Kurokawa, J. P. Gong and Y. Osada, "Substrate Effect on Topographical, Elastic, and Frictional Properties of Hydrogels", Macromolecules, 2002, 35, 8161-8166;

17. T. Tominaga, N. Takedomi, H. Biederman, H. Furukawa, Y. Osada and J. P. Gong, "Effect of substrate adhesion an hydrophobicity on hydrogel friction", Soft Matter, 2008, 4, 1033-1040;

18. J. A. Nott, "Settlement of barnacle larvae: surface structure of the antennular attachment disk by scanning electron microscopy", Marine Biol., 1969, 2, 248-251.

19. E. Yoshimura, Y. Nogata and I. Sakaguchi, "Simple methods for mass culture of barnacle larvae", Sessile Org, 2006, 2, 91-94.

20. M. K. Chaudhury and A. Chaudhury, "Super spreading of oil by condensed water drops", Soft Matter, 2005, 1, 431-435.

21. R. E. Baier, "Surface behaviour of biomaterials: The theta surface for biocompatibility", $J$ Mater Med, 2006, 17, 1057-1062.

22. M. Berglin and P. Gatenholm, "The barnacle adhesive plaque: morphological and chemical differences as a response to substrate properties", Colloids Surf B: Biointerfaces, 2003, $28,107-117$.

23. D. Rittschof, and J. D. Costlow, "Bryozoan and barnacle settlement in relation to initial surface wetability: a comparison of laboratory and field studies", In: Ros, E. D. (ed.) Topics in marine biology, 1989, 53, 411-416 


\section{Figure captions}

Fig. 1. Illustration of the cyprid settlement experiment using polystyrene (PS) petri dish system. The cyprid larvae metamorphosed into juvenile barnacles were termed as "settled". No cypris was found to settle on the wall of the petri dish covered with agarose gel.

Fig. 2. (a) Settlement ratio (\%) of barnacles on PAMPS/PAAm DN gels, PDMS, and PS after 1, 3, 5 and 7 days exposure. (b) Settlement ratio (\%) of barnacles on PAMPS/PAAm DN gels, PDMSs, and PS as a function of elastic modulus after 7 days exposure.

Fig. 3. The distribution of the basal diameter of barnacles on PS, PDMS and PAMPS/PAAm DN gel with different elastic moduli within 70 days duration at $0,14,42$ and 70 day. The numbers (n) in the figures mean the total number of barnacles remained on the substrates.

Fig. 4. Increase of the average basal diameter of barnacles with time on each substrate under different feeding conditions, feeding with diatom and brine shrimp. The vertical broken line means the boundary between two feeding conditions.

Fig. 5. Changes of average basal diameter of barnacles with the elastic moduli of substrates on day 14 (a), day 42 (b), and day 70 (c) of the growth. The vertical bar means \pm standard deviation.

Fig. 6. (a) Self-release ratio (\%) of barnacles and (b) average released basal diameter on different PDMS substrates as a function of time. The standard deviation of the latter was within $\pm 0.30 \mathrm{~mm}$.

Fig. 7. Self release ratio (\%) of barnacles from the PDMS surface with different elastic moduli ( $\square$ ) at day 70 and the effect of elastic modulus of PDMS on the average basal diameter of barnacles spontaneously released from the substrate $(\bullet)$. 
Fig. 8. Basal plate morphology of barnacles on various substrates at day 70 .

\section{Supplementary Information}

Fig. S1 Increase of the average basal diameter of barnacles with time on each substrate under different feeding conditions, feeding with diatom and brine shrimp. The vertical broken line means the boundary between two feeding conditions. Error range was estimated from at least 2 barnacles and maximum 35 barnacles.

Fig. S2 Bar graph for the increase of the basal average basal diameter of barnacles on each substrate on $0,14,42$ and 70 day. Error range was estimated from at least 2 barnacles and maximum 35 barnacles. 


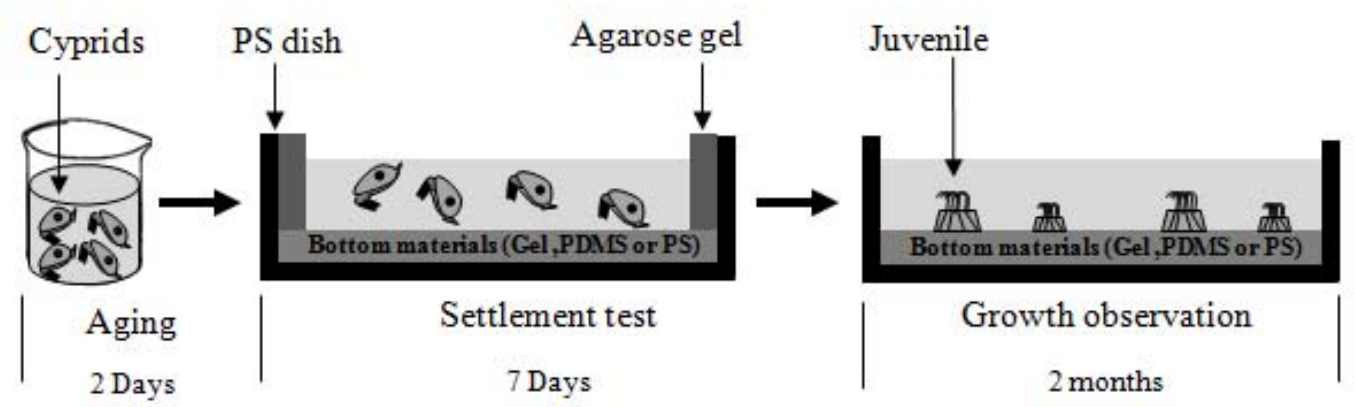

Fig. 1 


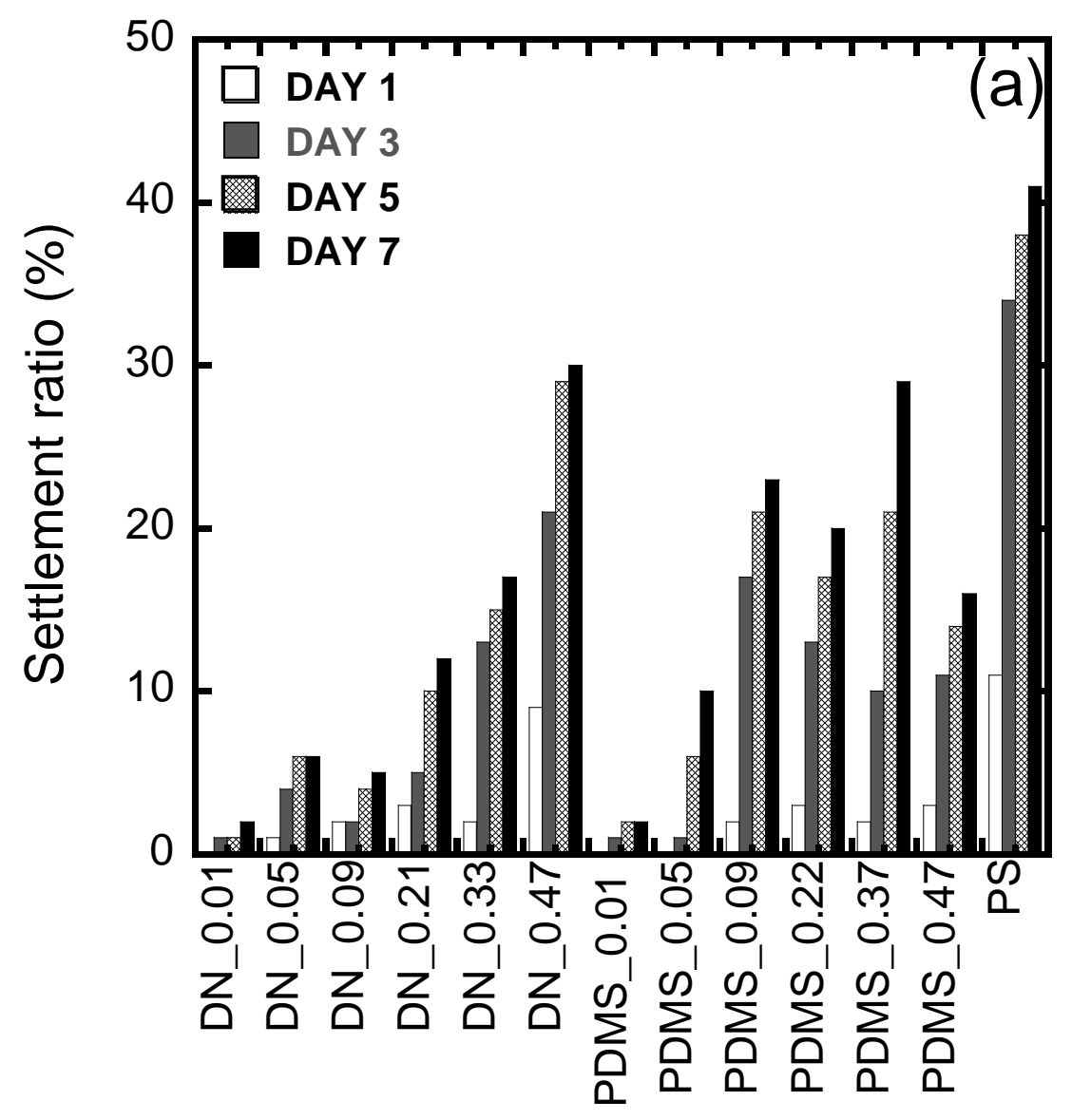

Substrates

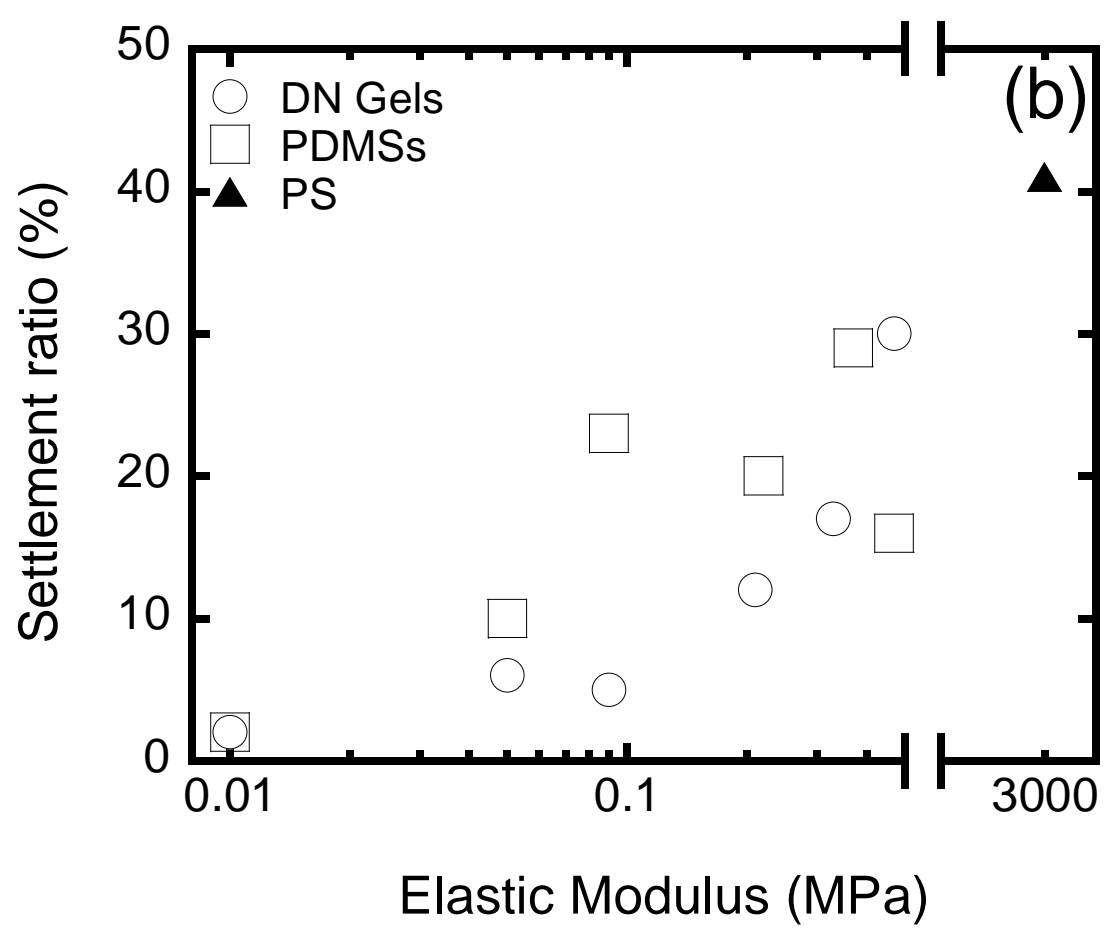

Fig. 2 

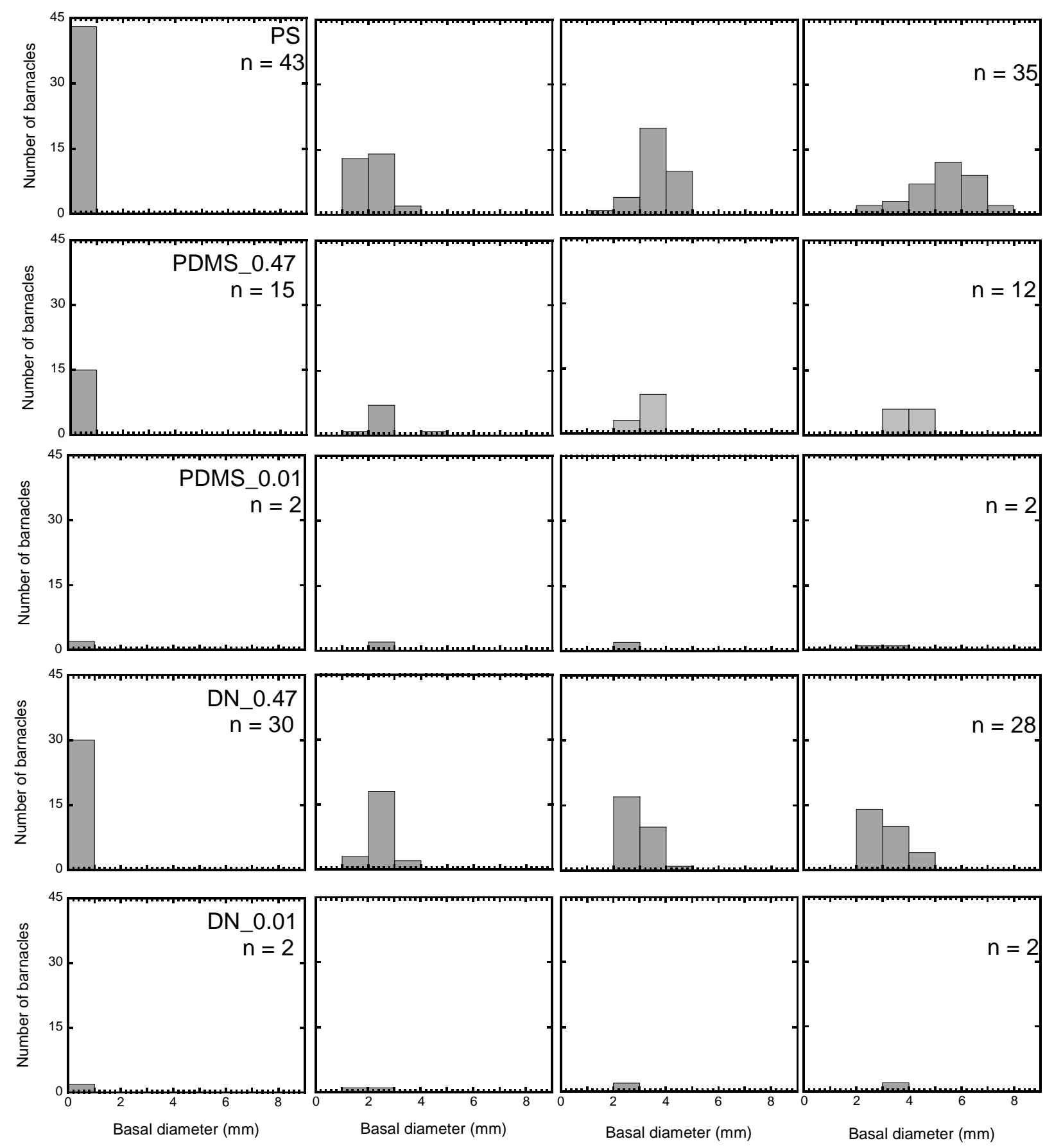

DAY 0

DAY 14

DAY 42

DAY 70

Fig. 3 


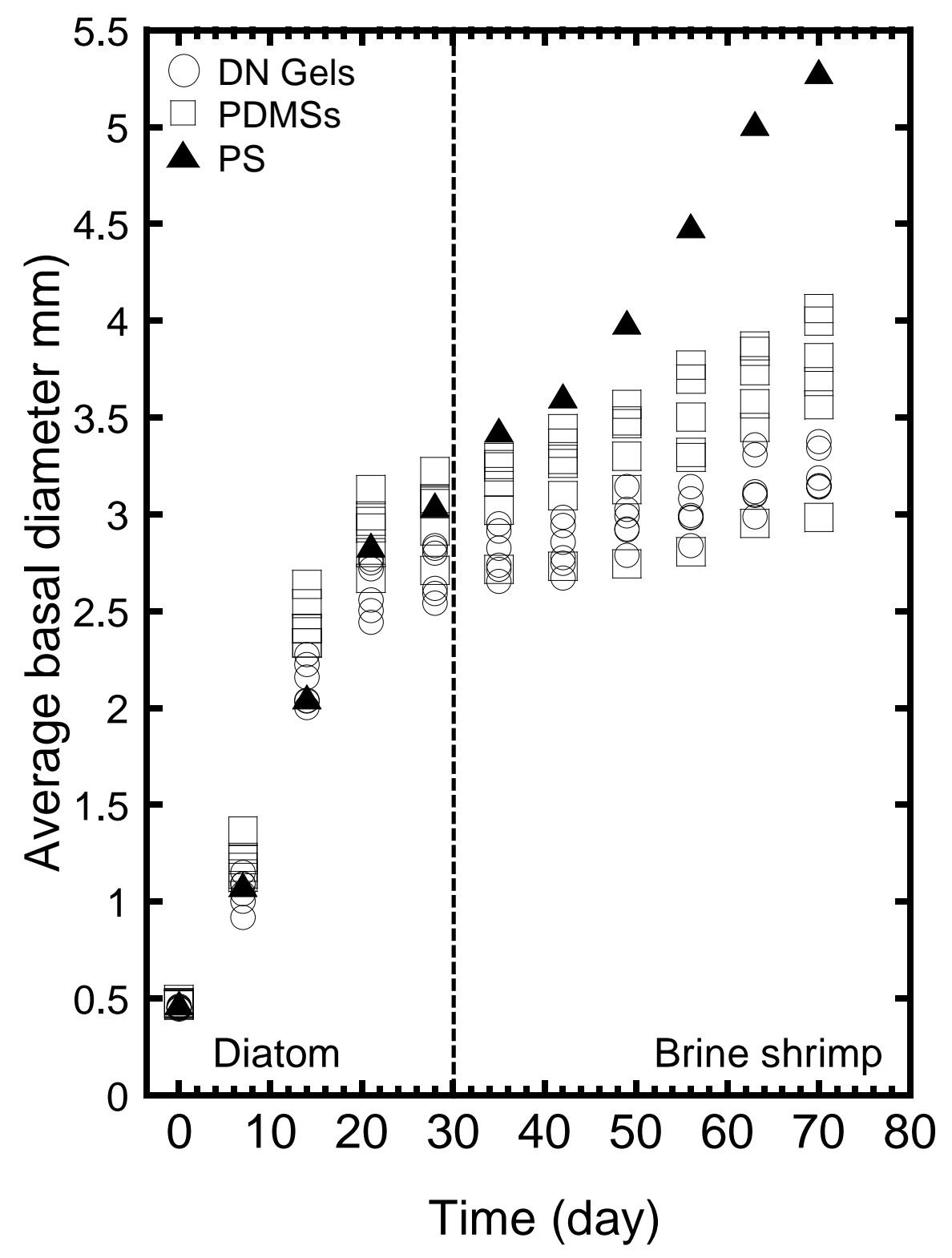

Fig. 4 

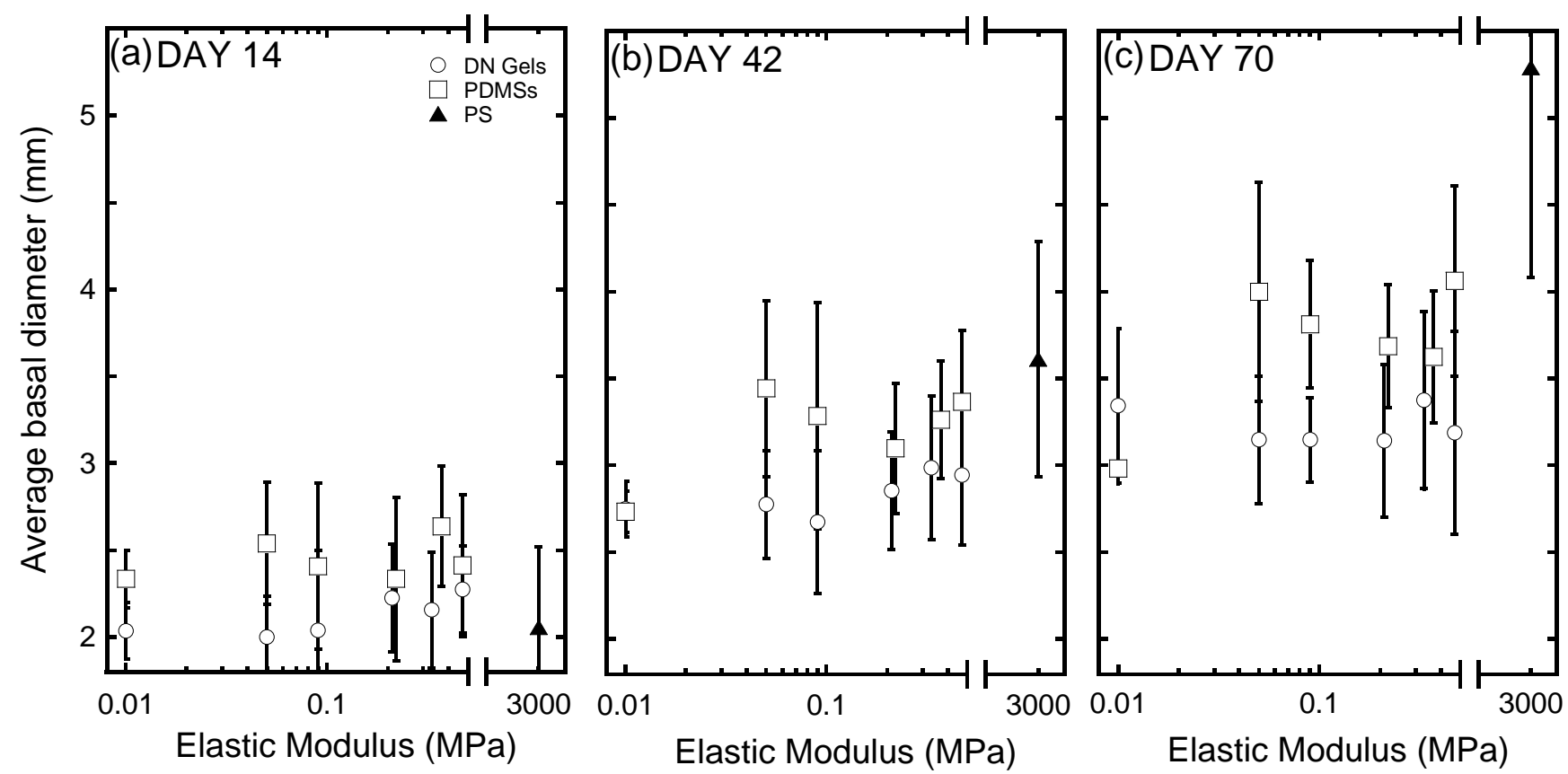

Fig. 5 

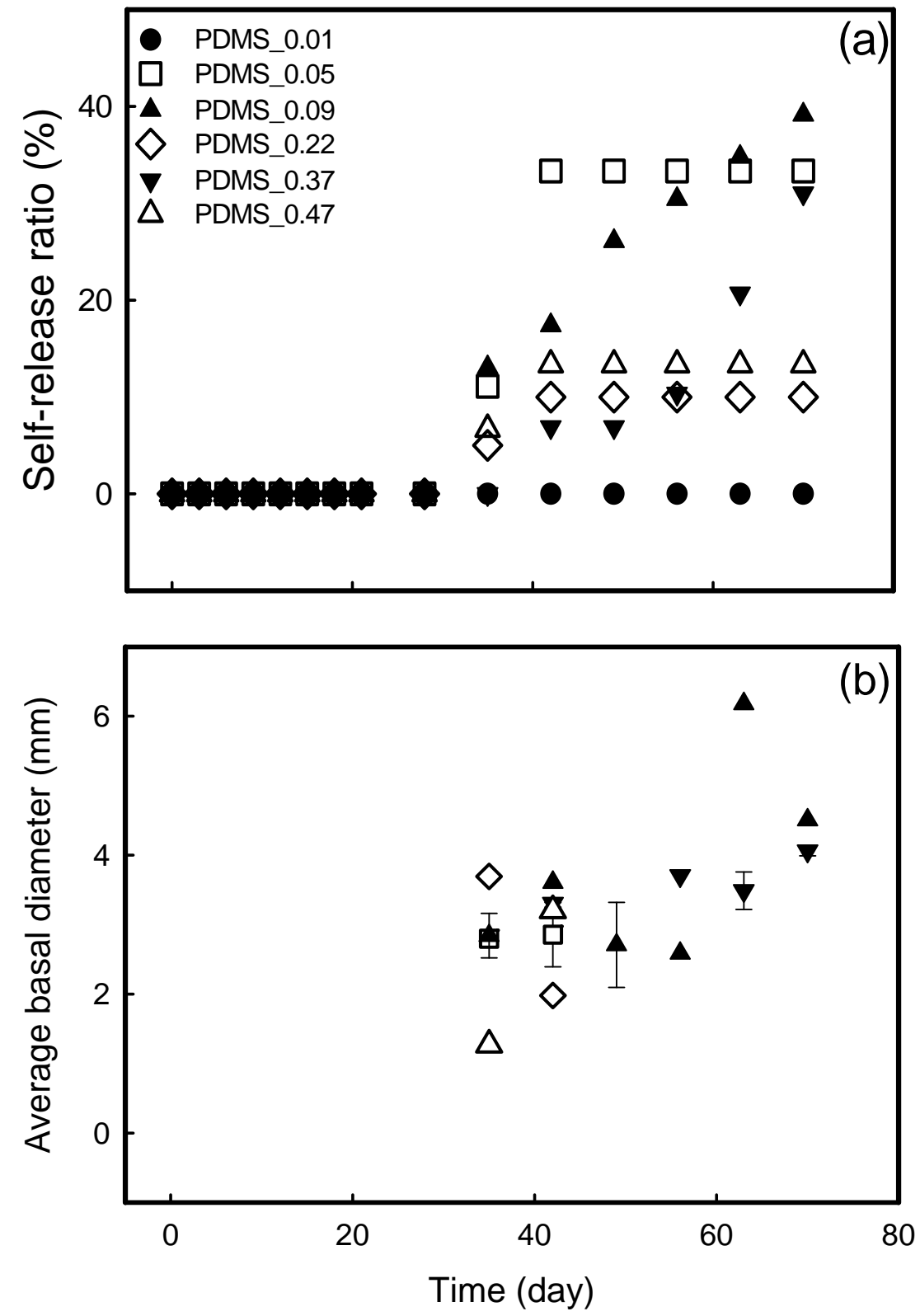

Fig. 6 


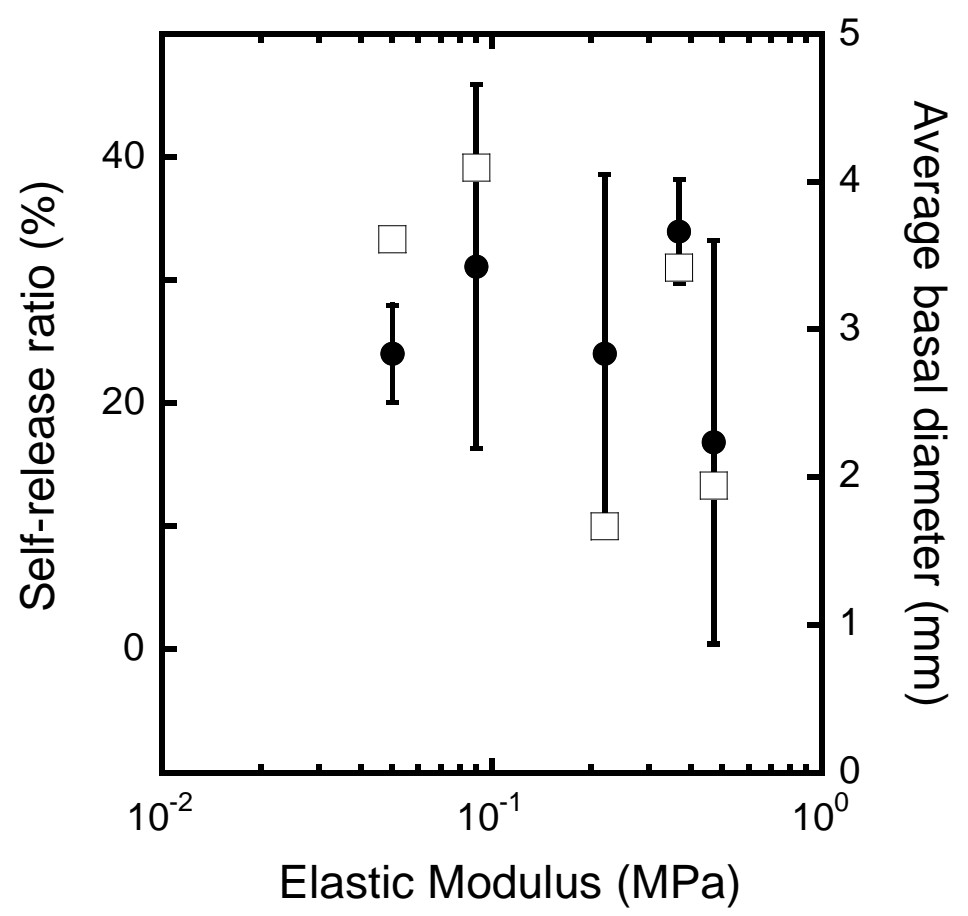

Fig. 7 

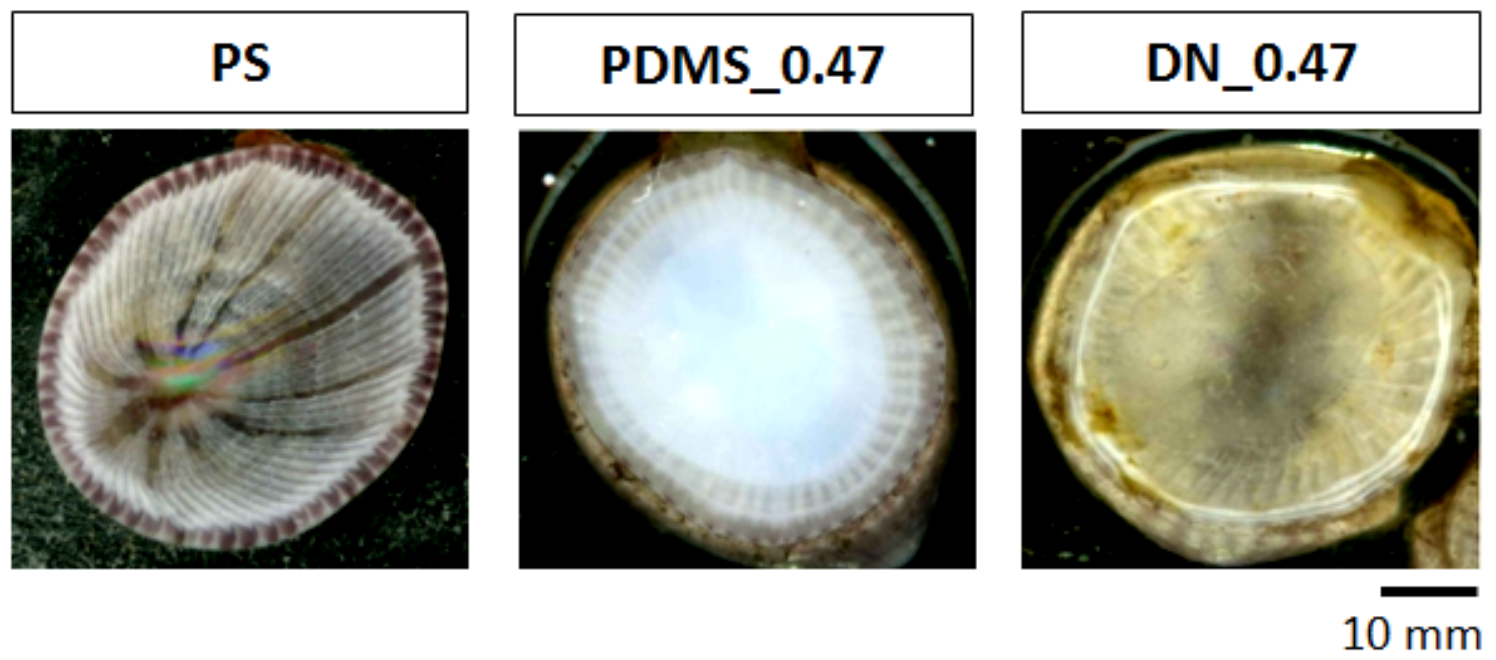

Figure 8 
Supplementary Information

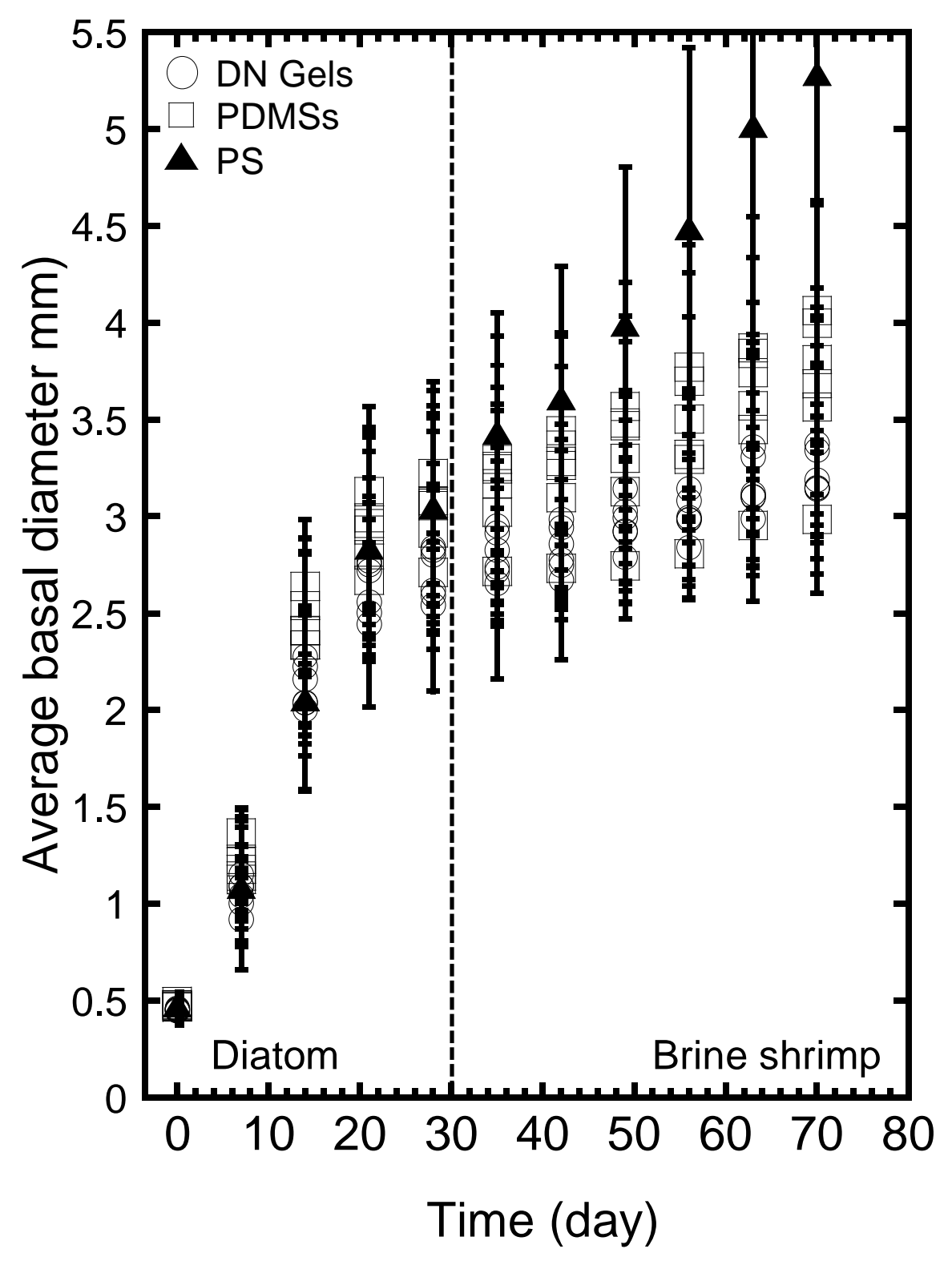

Fig. S1 


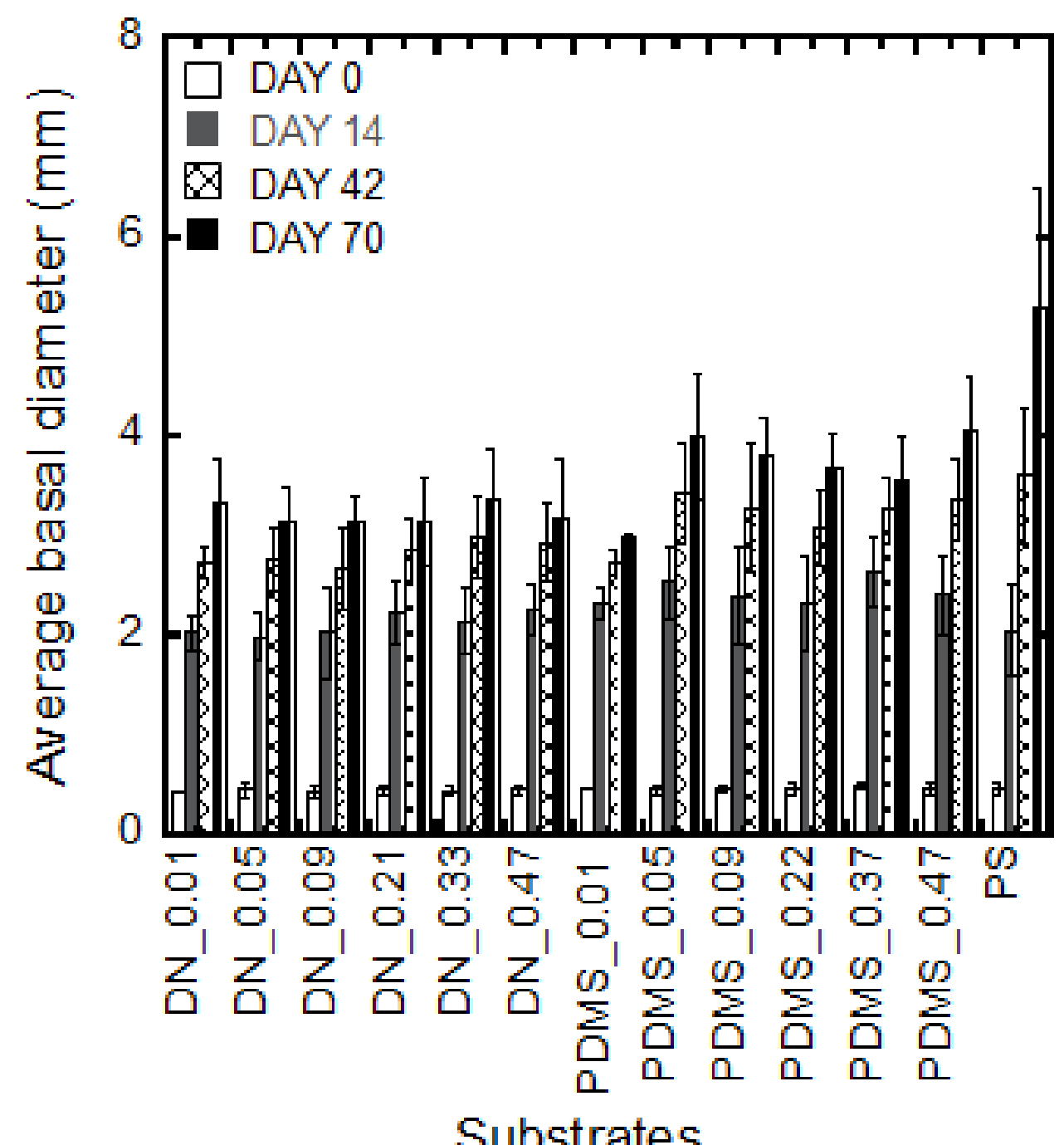

Fig. S2 